\title{
Deficiências de micronutrientes em crianças brasileiras assistidas em creches: revisão da literatura
}

\author{
Micronutrient deficiencies in Brazilian children \\ attending daycare centers: a review of the literature
}

Dixis Figueroa Pedraza ${ }^{1}$

Ana Carolina Dantas Rocha ${ }^{2}$

${ }^{1}$ Programa de PósGraduação em Saúde Pública, Universidade Estadual da Paraíba. Av. das Baraúnas 351, Bodocongó. 58109-753 Campina Grande PB Brasil. dixisfigueroa@gmail.com ${ }^{2}$ Programa de PósGraduação em Enfermagem, Universidade Federal do Ceará. Fortaleza CE Brasil.
Abstract The scope of the study was to review the scientific publications on the nutritional status of iron, vitamin A and zinc among Brazilian children attending daycare centers, focusing on diagnostic methods, the prevalence of respective deficiencies and associated factors. A review of the literature was conducted in the PubMed, LILACS and SciELO databases. Observational studies with random representative samples using biochemical indicators to evaluate the nutritional status of iron, vitamin $A$ and zinc of children attending public daycare centers were included. The average weighted prevalence for anemia and vitamin A deficiency was estimated. The variables associated with anemia were computed. Twenty-one observational studies were included, in which the nutritional status of iron, vitamin $A$ and zinc were analyzed in 17, 4 and 3, respectively. The average weighted prevalence of anemia and vitamin A deficiency were $42.7 \%$ and $12.5 \%$, respectively. Young children and children living in less favorable socioeconomic situations represented the main explanatory conditions predominantly associated with the occurrence of anemia. The results suggest a high prevalence of anemia, as well as vitamin A deficiency in Brazilian children attending daycare centers, with etiological prospects focused on infectious diseases.

Key words Micronutrients, Iron, Vitamin A, Zinc, Daycare centers
Resumo Objetivos: Revisar os artigos sobre o estado nutricional de ferro, vitamina $A$ e zinco em crianças brasileiras assistidas em creches, enfocando métodos diagnósticos, prevalências das respectivas deficiências e fatores associados. Métodos: A pesquisa de artigos foi efetuada nas bases PubMed, Lilacs e SciELO. Foram incluídos estudos observacionais com amostras representativas aleatórias que utilizaram indicadores bioquímicos para avaliar o estado nutricional de ferro, vitamina A e zinco de crianças assistidas em creches. Calcularam-se as prevalências médias ponderadas de anemia e de deficiência de vitamina $A$. Computaram-se as variáveis associadas à anemia. Resultados: Foram incluídos 21 estudos, nos quais $o$ estado nutricional de ferro, vitamina A e zinco foi analisado em 17, quatro e três, respectivamente. As prevalências médias ponderadas de anemia e de deficiência de vitamina A foram de 42,7\% e 12,5\%, respectivamente. Crianças de menor idade e de pior condição socioeconômica representaram as principais condições explicativas para a ocorrência de anemia. Conclusões: Os resultados sugerem altas prevalências de anemia e de deficiência de vitamina A entre as crianças brasileiras assistidas em creches com perspectivas etiológicas centradas nas doenças infecciosas.

Palavras-chave Micronutrientes, Ferro, Vitamina A, Zinco, Creches 


\section{Introdução}

As creches têm como objeto as relações educativas, decorrentes da função indissociável do cuidar/educar, que visam à garantia dos direitos e das necessidades próprias das crianças. As atividades realizadas nas creches direcionam-se ao desenvolvimento integral da criança em seus aspectos físico, psicológico, intelectual e social, num espaço de convívio coletivo que tem como sujeito a criança e cujo trabalho deve ser desenvolvido em parceria dos profissionais com a família ${ }^{1}$. Além disso, as creches são consideradas como uma das estratégias dos países em desenvolvimento para aprimorar o crescimento e o desenvolvimento das crianças pertencentes aos estratos sociais menos favorecidos ${ }^{2,3}$.

No Brasil, principalmente nas grandes e médias cidades, a demanda por esses serviços é grande e tende a aumentar com a participação crescente da mulher no mercado de trabalho. Essa procura tem produzido um aumento expressivo no número de creches e de crianças com o benefício no país ${ }^{3-5}$. Porém, o aumento do número de creches no Brasil vem acontecendo sem a intensificação necessária da vigilância eficaz sobre as normas que regulamentam sua implantação e funcionamento, como também com carência de profissionais capacitados para o desenvolvimento das atividades ${ }^{4,6,7}$. Esses aspectos, considerando que as características dos programas, dos serviços ou dos cuidados oferecidos podem influenciar o impacto desejado ${ }^{8}$, bem como o fato de o bem -estar da criança depender principalmente da alimentação, dos cuidados e do ambiente onde está inserida ${ }^{6,8,9}$, podem contribuir de forma negativa na consecução dos objetivos das creches e prejudicar, portanto, a saúde infantil.

A associação positiva entre frequentar creche e o estado nutricional tem sido sugerida, indicando-se redução dos déficits de peso e estatura ${ }^{5}$. Entretanto, as crianças que frequentam creches adoecem mais do que aquelas cuidadas exclusivamente em casa, sendo as doenças infecto-contagiosas as mais prevalentes, o que pode repercutir negativamente no seu estado nutricional, principalmente daquelas abaixo de 24 meses $^{2,4}$. Os problemas alimentares e nutricionais que gravitam em torno destas crianças distinguem-se por um quadro de fatores de risco dominado pelo binômio desnutrição/infecção, que afeta, principalmente, as crianças social e economicamente vulneráveis ${ }^{10}$. Apresentam-se, assim, posições não conclusivas sobre o estado nutricional das crianças que são assistidas em creches em comparação às de similar condição socioeconômica que não têm o benefício.

A alimentação representa uma das grandes responsabilidades da creche, devendo garantir o acesso a uma alimentação quantitativa e qualitativamente adequada ${ }^{7,11}$. Entretanto, estudos sobre consumo alimentar com crianças matriculadas em creches de diferentes regiões do país têm mostrado baixa ingestão dietética de alguns nutrientes como cálcio, ferro, vitamina A, fibras e energia ${ }^{3}$. Adverte-se, assim, a probabilidade de carências nutricionais nas crianças institucionalizadas, considerando a influência da composição da dieta infantil no estado nutricional ${ }^{3,12}$. No Brasil, a prevalência de desnutrição proteico-energética tem diminuído ${ }^{13,14}$, contudo o mesmo não tem acontecido com as carências específicas de ferro, vitamina A e zinco ${ }^{15,16}$, determinantes importantes do crescimento linear', sem se conhecer a situação específica das crianças assistidas em creches.

Face ao exposto, o objetivo deste estudo é revisar os artigos sobre o estado nutricional de ferro, vitamina A e zinco de crianças brasileiras assistidas em creches, enfocando métodos diagnósticos, prevalências das respectivas deficiências e fatores associados.

\section{Métodos}

A revisão da literatura foi realizada a partir de um levantamento bibliográfico nas bases de dados PubMed (National Library of Medicine, Estados Unidos), Lilacs (Literatura Latino-americana e do Caribe em Ciências da Saúde) e SciELO (Scientific Electronic Library Online). Na busca utilizaram-se os termos (Micronutrients OR Vitamin A OR Iron OR Zinc OR Vitamin A Deficiency OR Iron Deficiency OR Anemia OR Zinc Deficiency) AND Child day care centers. No caso do PubMed, o descritor Brazil também foi usado. Os artigos publicados entre 2000 e 2014 foram investigados, aceitando-se aqueles escritos em português, inglês e espanhol. A busca foi realizada em 12/07/2014 e realizada por dois revisores de forma independente.

Para o cômputo do total de estudos identificados, foi verificada a duplicação dos mesmos entre as bases de dados, sendo cada artigo contabilizado somente uma vez. Foram incluídos estudos observacionais realizados no Brasil com amostras representativas aleatórias que utilizaram indicadores bioquímicos para avaliar como desfecho o estado nutricional de micronutrientes 
(ferro, vitamina A, zinco) de crianças assistidas em creches (sem distinção se pública ou privada). A decisão sobre a inclusão dos artigos incluiu duas etapas: i) triagem por meio da leitura dos títulos e resumos, ii) leitura na íntegra. Na primeira etapa, dos 110 documentos identificados (dos 158 documentos encontrados nas bases de dados pesquisadas 48 duplicados estam duplicados), 49 foram excluídos: 26 estudos de intervenção, 04 artigos de revisão, 13 livros ou teses, 04 estudos realizados fora do Brasil, 02 trabalhos desenvolvidos com crianças não assistidas em creches. $\mathrm{Na}$ segunda etapa, foram excluídos 11 estudos com amostras não representativas e/ou não selecionadas aleatoriamente e 29 artigos sem o uso de indicadores bioquímicos do estado nutricional de ferro, vitamina A ou zinco. Assim, com a exclusão de um total de 89 documentos, 21 artigos foram considerados incluídos. O fluxo relacionado à identificação e seleção dos estudos encontra-se na Figura 1.

Os estudos incluídos foram caracterizados segundo autor e ano de publicação, tipo de estudo, local de estudo, faixa etária, tamanho da amostra e perdas, indicadores bioquímicos e técnicas de análises utilizados, critérios de diagnóstico (pontos de corte), variáveis controladas e principais resultados (prevalências e resultados estatísticos significantes).

Foram calculadas, para os casos dos estudos sobre o estado nutricional de ferro e de vitamina A, por meio de metanálise, as prevalências médias ponderadas de anemia e de deficiência de vitamina A pelos respectivos tamanhos amostrais e as amplitudes correspondentes. Também foram computadas as variáveis para verificar os fatores que mais se associaram à anemia (a carência de estudos/resultados para a vitamina A e o zinco inviabilizou o procedimento para esses micronutrientes).

\section{Resultados}

O Quadro 1 mostra a distribuição dos 21 estudos incluídos na revisão ${ }^{17-37}$, todos de delineamento

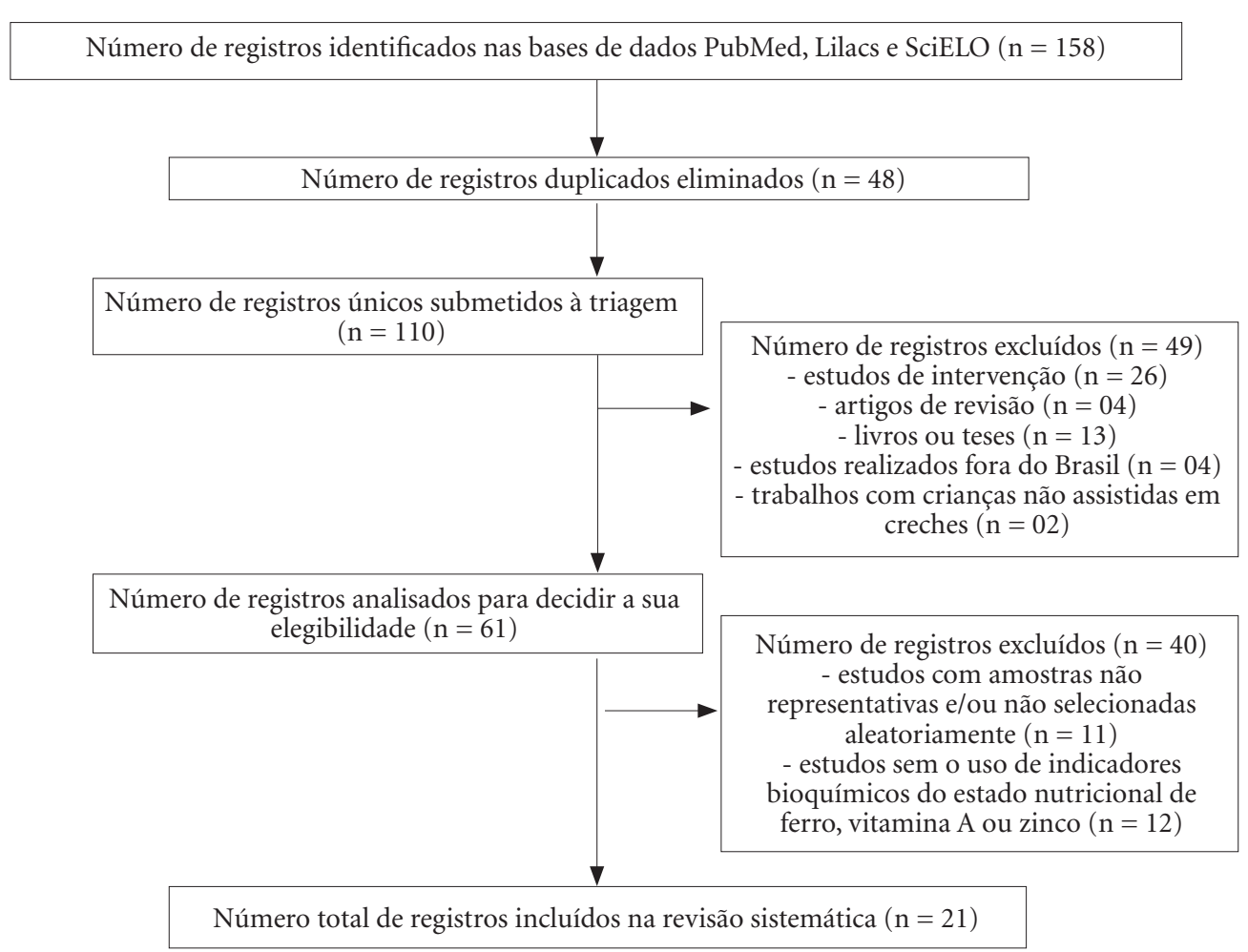

Figura 1. Fluxograma das fases de identificação, triagem e seleção de artigos sobre o estado nutricional de ferro, vitamina A e zinco de crianças brasileiras assistidas em creches. 
transversal quanto aos parâmetros de caracterização adotados. A distribuição geográfica dos locais de realização dos estudos mostra maior concentração na região Sudeste $e^{17,21,22,24-26,28-31,37}$.

Quadro 1. Características dos artigos sobre o estado nutricional de ferro, vitamina A e zinco de crianças brasileiras assistidas em creches.

\begin{tabular}{|c|c|c|c|c|c|c|c|c|}
\hline $\begin{array}{c}\text { Autores, } \\
\text { ano }\end{array}$ & $\begin{array}{l}\text { Local de } \\
\text { estudo }\end{array}$ & $\begin{array}{l}\text { Faixa } \\
\text { etária }\end{array}$ & $\begin{array}{c}\text { Amostra } \\
\text { (perdas) }\end{array}$ & $\begin{array}{c}\text { Indicadores } \\
\text { bioquímicos e } \\
\text { técnicas de análises }\end{array}$ & $\begin{array}{l}\text { Pontos de } \\
\text { corte }\end{array}$ & $\begin{array}{c}\text { Variáveis } \\
\text { controladas } \\
\text { (modelo } \\
\text { final) }\end{array}$ & $\begin{array}{c}\text { Prevalências } \\
\text { (\%) }\end{array}$ & $\begin{array}{c}\text { Resultados } \\
\text { estatísticos } \\
\text { significantes }^{*}\end{array}$ \\
\hline $\begin{array}{l}\text { Magalhães et } \\
\text { al., 2001 }\end{array}$ & $\begin{array}{l}\text { Viçosa } \\
(\mathrm{MG}) \\
3 \text { creches } \\
\text { municipais }\end{array}$ & 3-6 anos & 135 & $\begin{array}{l}\text { - Hb: Cianometa- } \\
\text { hemoglobina } \\
\text { - Ht: } \\
\text { Microhematócrito } \\
\text { - FER: } \\
\text { Imunofluorimétrico } \\
\text { DELFIA } \\
\text { - RS: } \\
\text { Espectrofotômetro } \\
\text { de Bessey-Lowry, } \\
\text { modificado por } \\
\text { Araújo e Flores }\end{array}$ & $\begin{array}{l}\text { - Anemia: } \\
\mathrm{Hb}<11 \\
\text { g/dL } \\
\text { - Anemia } \\
\text { grave: } \mathrm{Hb} \\
<10 \mathrm{~g} / \mathrm{dL} \\
-\mathrm{Ht}< \\
33 \% \\
-\mathrm{FER}< \\
10 \mathrm{ng} / \mathrm{mL} \\
-\mathrm{RS} \\
<0,70 \\
\mu \mathrm{mol} / \mathrm{L}\end{array}$ & - & $\begin{array}{l}\text { - Anemia: } \\
\text { 10,4 } \\
\text { - Anemia } \\
\text { grave: } 2 \\
\text { - Ht baixo: } \\
5,7 \\
\text { - FER baixa: } \\
\text { 17,4 } \\
\text { - DVA: } 15,0\end{array}$ & $\begin{array}{l}\text { Correlação } \\
\text { significativa entre } \\
\text { os níveis de Hb e } \\
\text { RS: } p=0,022\end{array}$ \\
\hline $\begin{array}{l}\text { Silva et al., } \\
2001^{18}\end{array}$ & $\begin{array}{l}\text { Porto } \\
\text { Alegre (RS) } \\
29 \text { escolas } \\
\text { municipais } \\
\text { infantis }\end{array}$ & $\begin{array}{l}0-36 \\
\text { meses }\end{array}$ & $\begin{array}{l}573 \\
(16)\end{array}$ & $\begin{array}{l}\text { - Hb: Fotômetro } \\
\text { portátil HemoCue }\end{array}$ & $\begin{array}{l}\text { - Anemia: } \\
\mathrm{Hb}<11 \\
\mathrm{~g} / \mathrm{dL}\end{array}$ & $\begin{array}{l}\text { Uso de um } \\
\text { modelo } \\
\text { teórico } \\
\text { definido } \\
\text { a priori, } \\
\text { agrupadas } \\
\text { as variáveis } \\
\text { em blocos+ }\end{array}$ & $\begin{array}{l}\text { - Anemia: } \\
47,8\end{array}$ & 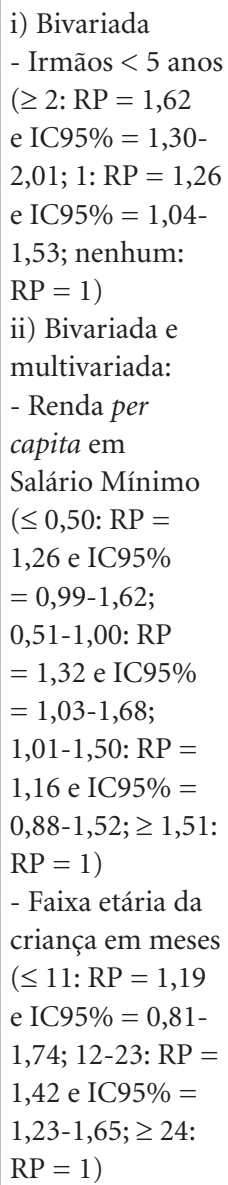 \\
\hline
\end{tabular}


Os demais estudos foram realizados na região Nordeste $e^{20,23,27,32-34,36}$, Sul ${ }^{18,35}$ e Centro-Oeste ${ }^{19}$. Considerando o tipo de creche, a maioria dos estudos realizou-se exclusivamente nas públicas (municipais ou estaduais) ${ }^{17,18,20-25,27,30,32-36}$. A faixa etária apresentou homogeneidade. Considerando a idade, observa-se que a maioria dos estu$\operatorname{dos}^{18,19,21,23-28,29,31,32,34-37}$ envolveu crianças menores de dois anos, dos quais cinco ${ }^{18,19,31,32,35}$ limitaramse a crianças de até três anos.

Com relação aos indicadores bioquímicos utilizados para caracterizar o estado nutricional das crianças, poucos estudos avaliaram as concentrações de zinco ${ }^{20,34,36}$ ou de retinol séri$\mathrm{co}^{17,23,33,36}$. Em contrapartida, a maioria dos estu- $\operatorname{dos}^{17-19,21,22,24-32,35-37}$ avaliou o estado nutricional de ferro, com dosagem de hemoglobina ( $\mathrm{Hb}$ ) em todos; a ferritina sérica (FER) 17,21,27,32 e o índice de

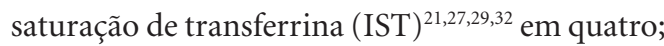
o receptores de transferrina (RT) $)^{21,32,35}$, o volume corpuscular médio $(\mathrm{VCM})^{26,32,35}$ e o ferro sérico $(\mathrm{FeS})^{27,29,35}$ em três; a capacidade total de ligação de ferro (CTLF ${ }^{27,29}$ em dois estudos; e o hematocrito $(\mathrm{Ht})^{17}$, o coeficiente de variação do volume eritrocitário $(\mathrm{CVVE})^{26} \mathrm{e}$ a proto-porfirina eritrocitária livre $(\mathrm{PEL})^{27} \mathrm{em}$ apenas um dos estudos.

Quanto às técnicas de análises dos indicadores bioquímicos, as concentrações de zinco no cabelo, zinco sérico e Fosfatasse Alcalina (FA) foram determinadas por espectrofotometria de ab-

\begin{tabular}{|c|c|c|c|c|c|c|c|c|}
\hline \multicolumn{9}{|c|}{ Quadro 1. continuação } \\
\hline $\begin{array}{l}\text { Autores, } \\
\text { ano }\end{array}$ & $\begin{array}{l}\text { Local de } \\
\text { estudo }\end{array}$ & $\begin{array}{l}\text { Faixa } \\
\text { etária }\end{array}$ & $\begin{array}{l}\text { Amostra } \\
\text { (perdas) }\end{array}$ & $\begin{array}{c}\text { Indicadores } \\
\text { bioquímicos e } \\
\text { técnicas de análises }\end{array}$ & $\begin{array}{c}\text { Pontos de } \\
\text { corte }\end{array}$ & $\begin{array}{c}\text { Variáveis } \\
\text { controladas } \\
\text { (modelo } \\
\text { final) }\end{array}$ & $\begin{array}{c}\text { Prevalências } \\
(\%)\end{array}$ & $\begin{array}{c}\text { Resultados } \\
\text { estatísticos } \\
\text { significantes }^{*}\end{array}$ \\
\hline $\begin{array}{l}\text { Brunken et al., } \\
2002^{19}\end{array}$ & $\begin{array}{l}\text { Cuiabá } \\
\text { (MT) } \\
8 \text { creches } \\
\text { municipais } \\
2 \text { centros de } \\
\text { atenção à } \\
\text { criança } \\
1 \text { creche } \\
\text { filantrópica }\end{array}$ & $\begin{array}{l}2-36 \\
\text { meses }\end{array}$ & 271 & - Hb: NR & $\begin{array}{l}\text { - Anemia: } \\
\mathrm{Hb}<11 \mathrm{~g} / \\
\mathrm{dL} \\
\text { - Anemia } \\
\text { grave: } \mathrm{Hb} \\
<9,5 \mathrm{~g} / \mathrm{dL}\end{array}$ & \begin{tabular}{|l|} 
A \\
associação \\
com o \\
Escore-Z \\
de estatura/ \\
idade foi \\
controlada \\
para a idade \\
da criança
\end{tabular} & $\begin{array}{l}\text { - Anemia: } \\
63,1 \\
\text { - Anemia } \\
\text { grave: } 22,5 \\
\\
\end{array}$ & $\begin{array}{l}\text { - Faixa etária da } \\
\text { criança em meses: } \\
\mathrm{p}<0,0001 \text { (menor } \\
\text { prevalência em } \\
>24) \\
\text { - Escore-Z de } \\
\text { estatura/idade } \\
(<-2: \mathrm{RP}=1,27 \\
\text { e IC95\% }=1,06- \\
1,53 ; \geq-2: \mathrm{RP}=1 ; \\
\mathrm{p}=0,0139) \\
\text { - Escore-Z de } \\
\text { peso/idade }(< \\
-2: \mathrm{RP}=1,73 \mathrm{e} \\
\mathrm{IC} 95 \%=1,55- \\
1,93 ; \geq-2: \mathrm{RP}=1 ; \\
\mathrm{p}=0,0018) \\
\text { - Tempo de creche } \\
\text { em meses }(\leq 4: \mathrm{RP} \\
=1,27 \text { e IC95\% } \\
0,98-1,63 ;>4: \mathrm{RP} \\
=1 ; \mathrm{p}=0,0455)\end{array}$ \\
\hline $\begin{array}{l}\text { Silva-Santana } \\
\text { et al., } 2002^{20}\end{array}$ & $\begin{array}{l}\text { João Pessoa } \\
(\mathrm{PB}) \\
24 \text { creches } \\
\text { municipais }\end{array}$ & $2-5$ anos & 377 & $\begin{array}{l}\text { - Zn Cabelo, FA: } \\
\text { Espectrofotometria } \\
\text { de absorção atômica }\end{array}$ & $\begin{array}{l}-\mathrm{Zn} \\
\text { Cabelo } \\
<1,68 \\
\mu \mathrm{mol} / \mathrm{g} \\
-\mathrm{FA}< \\
250 \mathrm{U} / \mathrm{L}\end{array}$ & - & $\begin{array}{l}\text { - Déficit de } \\
\text { Zn Cabelo: } \\
61,9 \\
\text { - Deficiência } \\
\text { de atividade } \\
\text { da FA: } 40,1\end{array}$ & $\begin{array}{l}\text { Não foram } \\
\text { encontrados } \\
\text { resultados } \\
\text { estatísticos } \\
\text { significantes para } \\
\text { as variáveis de } \\
\text { estudo: sexo e } \\
\text { idade da criança }\end{array}$ \\
\hline
\end{tabular}




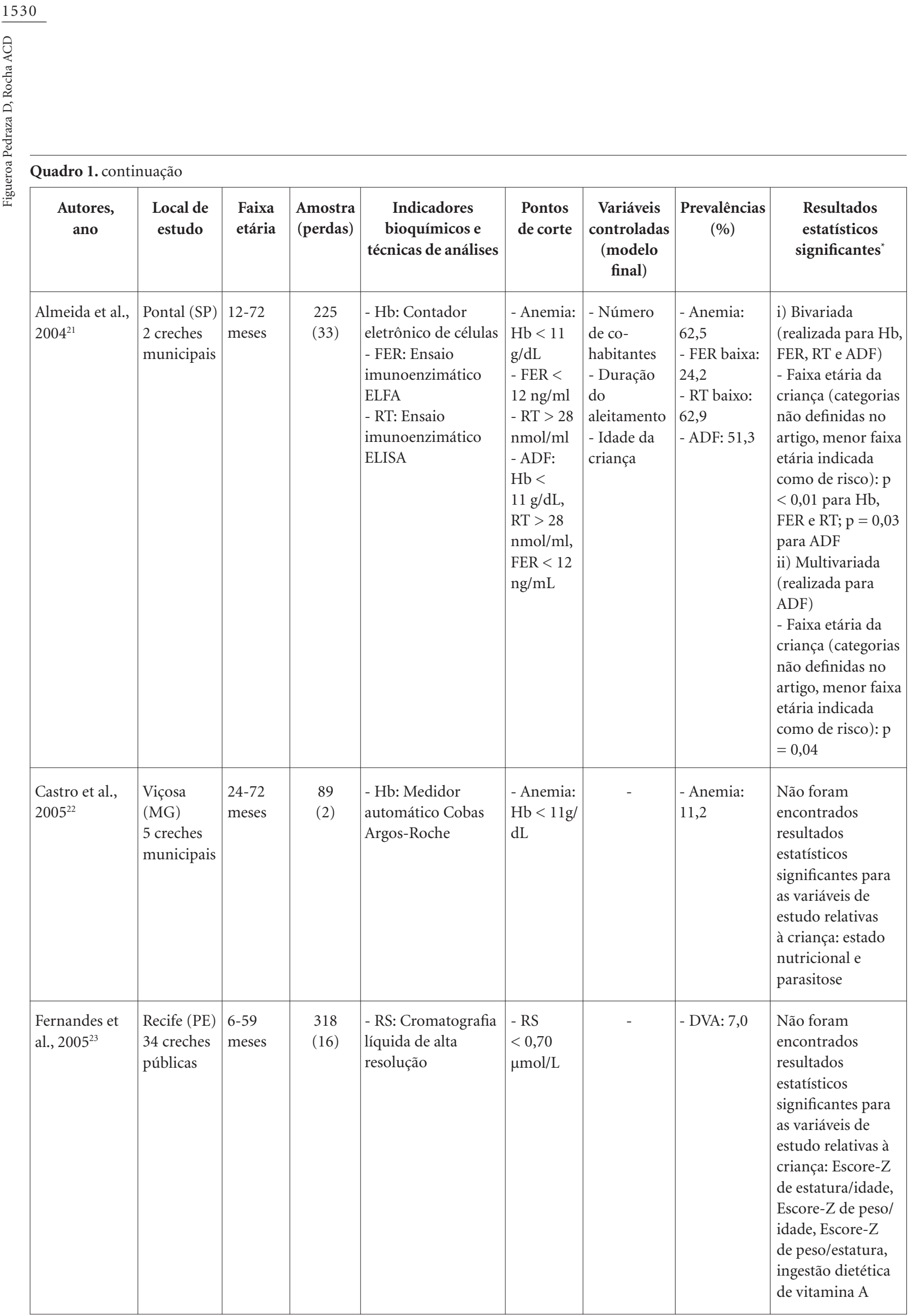




\begin{tabular}{|c|c|c|c|c|c|c|c|c|}
\hline \multicolumn{9}{|c|}{ Quadro 1. continuação } \\
\hline $\begin{array}{c}\text { Autores, } \\
\text { ano }\end{array}$ & $\begin{array}{l}\text { Local de } \\
\text { estudo }\end{array}$ & $\begin{array}{l}\text { Faixa } \\
\text { etária }\end{array}$ & $\begin{array}{l}\text { Amostra } \\
\text { (perdas) }\end{array}$ & $\begin{array}{c}\text { Indicadores } \\
\text { bioquímicos e } \\
\text { técnicas de análises }\end{array}$ & $\begin{array}{l}\text { Pontos } \\
\text { de corte }\end{array}$ & $\begin{array}{c}\text { Variáveis } \\
\text { controladas } \\
\text { (modelo } \\
\text { final) }\end{array}$ & $\begin{array}{c}\text { Prevalências } \\
(\%)\end{array}$ & $\begin{array}{c}\text { Resultados } \\
\text { estatísticos } \\
\text { significantes }^{*}\end{array}$ \\
\hline $\begin{array}{l}\text { Matta et al., } \\
2005^{24}\end{array}$ & $\begin{array}{l}\text { Rio de } \\
\text { Janeiro } \\
(\mathrm{RJ}) \\
9 \text { creches } \\
\text { municipais }\end{array}$ & $0-5$ anos & $\begin{array}{l}1217 \\
(328)\end{array}$ & $\begin{array}{l}\text { - Hb: Fotômetro } \\
\text { portátil HemoCue }\end{array}$ & $\begin{array}{l}\geq 6 \text { meses } \\
- \text { Anemia: } \\
\mathrm{Hb}<11 \mathrm{~g} / \\
\mathrm{dL} \\
<6 \text { meses } \\
- \text { Anemia: } \\
\mathrm{Hb}< \\
9,5 \mathrm{~g} / \mathrm{dL}\end{array}$ & $\begin{array}{l}\text { - Idade da } \\
\text { criança } \\
\text { - Educação } \\
\text { paterna } \\
\text { - Número } \\
\text { de } \\
\text { residentes } \\
\text { no } \\
\text { domicílio }\end{array}$ & $\begin{array}{l}\text { - Anemia: } \\
47,3\end{array}$ & 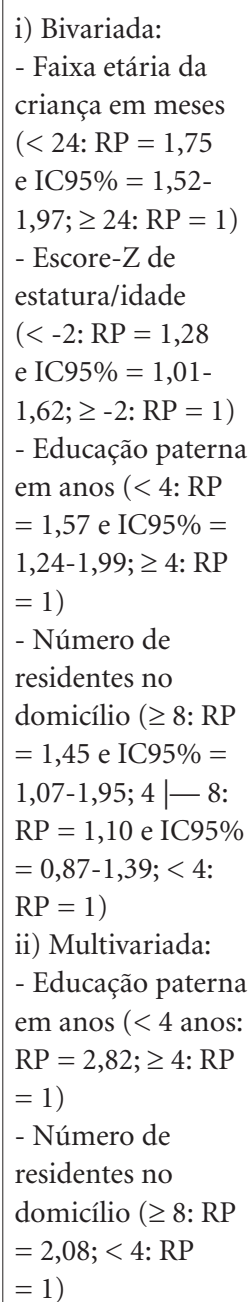 \\
\hline
\end{tabular}

sorção atômica. A cromatografia líquida de alta resolução ${ }^{23,33,36}$ foi o principal método em relação ao retinol sérico. Os valores de $\mathrm{Hb}$, por sua vez, foram analisados por diferentes técnicas, sendo o fotômetro portátil HemoCue $\mathrm{H}^{18,24,25,28,30,31,37}$ e o contador automático de células ${ }^{26,32,36}$ as mais usadas. Para a FER, o IST, o RT, o VCM e a CTLF, houve diversidade de técnicas nos estudos que utilizaram os respectivos parâmetros.

Os pontos de corte usados para o diagnóstico de deficiência de zinco foram valores $<1,68$ $\mu \mathrm{mol} / \mathrm{g}$ de zinco no cabelo $^{20},<250 \mathrm{U} / \mathrm{L}$ de ativi- dade de $\mathrm{FA}^{20}$ e $<65 \mu \mathrm{g} / \mathrm{dL}$ de zinco no soro ${ }^{34,36}$. A deficiência de vitamina A foi considerada, em todos os estudos com tal avaliação, quando as concentrações de retinol sérico eram $<0,70 \mu \mathrm{mol} /$ $\mathrm{L}^{17,23,33,36}$. Para diagnosticar anemia, o ponto de corte mais usado foi $<11 \mathrm{~g} / \mathrm{dL}$ de $\mathrm{Hb}$, em 17 estu$\operatorname{dos}^{17-19,21,22,24-32,35-37}$. Três estudos ${ }^{21,26,32}$, com variedade de critérios, trabalharam com o diagnóstico de anemia por deficiência de ferro (ADF). Os pontos de corte e/ou unidades de medidas para FER, RT, VCM e FeS variaram nos estudos que utilizaram tais parâmetros. 
Quadro 1. continuação

\begin{tabular}{|c|c|c|c|c|c|c|c|c|}
\hline $\begin{array}{l}\text { Autores, } \\
\text { ano }\end{array}$ & $\begin{array}{l}\text { Local de } \\
\text { estudo }\end{array}$ & $\begin{array}{l}\text { Faixa } \\
\text { etária }\end{array}$ & $\begin{array}{c}\text { Amostra } \\
\text { (perdas) }\end{array}$ & $\begin{array}{c}\text { Indicadores } \\
\text { bioquímicos e } \\
\text { técnicas de análises }\end{array}$ & $\begin{array}{l}\text { Pontos de } \\
\text { corte }\end{array}$ & $\begin{array}{l}\text { Variáveis } \\
\text { controladas } \\
\text { (modelo } \\
\text { final) }\end{array}$ & $\begin{array}{c}\text { Prevalências } \\
(\%)\end{array}$ & $\begin{array}{c}\text { Resultados } \\
\text { estatísticos } \\
\text { significantes }^{*}\end{array}$ \\
\hline $\begin{array}{l}\text { Bueno et al., } \\
2006^{25}\end{array}$ & $\begin{array}{l}\text { São Paulo } \\
\text { (SP) } \\
20 \text { creches } \\
\text { públicas }\end{array}$ & $\begin{array}{l}\text { 6-75 } \\
\text { meses }\end{array}$ & 330 & $\begin{array}{l}\text { - Hb: } \\
\text { Hemoglobinômetro } \\
\text { portátil HemoCue }\end{array}$ & $\begin{array}{l}\text { - Anemia: } \mathrm{Hb} \\
<11 \mathrm{~g} / \mathrm{dL} \\
\text { - Anemia } \\
\text { grave: } \mathrm{Hb}< \\
\text { 9,5g/dL }\end{array}$ & $\begin{array}{l}\text { - Idade do } \\
\text { responsável } \\
\text { pela criança } \\
\text { - Prema- } \\
\text { turidade } \\
\text { - Tempo de } \\
\text { creche } \\
\text { - Peso ao } \\
\text { nascer } \\
\text { - Escore-Z } \\
\text { de estatura/ } \\
\text { idade } \\
\text { - Idade da } \\
\text { criança } \\
\text { - Sexo da } \\
\text { criança }\end{array}$ & $\begin{array}{l}\text { - Anemia: } \\
68,8 \\
\text { - Anemia } \\
\text { grave: } 26,9\end{array}$ & $\begin{array}{l}\text { i) Bivariada: } \\
\text { - Tempo de creche } \\
\text { em meses (<15: } \\
\mathrm{RP}=1,81 \text { e IC95\% } \\
=1,00-2,55 ; 15 \\
\mid-25: \mathrm{RP}=1,26 \\
\text { e IC95\% = 0,73- } \\
2,19 ; \geq 25: \mathrm{RP}=1) \\
\text { ii) Bivariada e } \\
\text { multivariada: } \\
\text { - Idade do } \\
\text { responsável pela } \\
\text { criança em anos } \\
(\geq 25: \mathrm{RP}=1,84 \\
\text { e IC95\% = 1,06- } \\
3,21 ; 25-\mid 30: \mathrm{RP} \\
=1,84 \text { e IC95\% } \\
0,99-3,42 ;>30: \mathrm{RP} \\
=1) \\
\text { - Faixa etária da } \\
\text { criança em meses } \\
(<24: \mathrm{RP}=2,73 \\
\text { e IC95\% = 1,45- } \\
5,15 ; \geq 24: \mathrm{RP}=1)\end{array}$ \\
\hline $\begin{array}{l}\text { Almeida et } \\
\text { al., } 2007^{26}\end{array}$ & $\begin{array}{l}\text { Jardinópolis } \\
\text { (SP) } \\
4 \text { creches } \\
\text { públicas } \\
1 \text { creche } \\
\text { filantrópica }\end{array}$ & $\begin{array}{l}12-59 \\
\text { meses }\end{array}$ & $\begin{array}{l}201 \\
(17)\end{array}$ & $\begin{array}{l}\text { - Hb, VCM, } \\
\text { CVVE: Contador } \\
\text { automático de } \\
\text { células Pentra } \\
\text { - IST: Método } \\
\text { indireto a partir da } \\
\text { razão entre FeS e } \\
\text { CTLF (obtidos pelo } \\
\text { método Ferrozine, } \\
\text { automação Cobas } \\
\text { Mira Plus Roche) } \\
\text { X } 100\end{array}$ & $\begin{array}{l}12-48,9 \text { meses } \\
\text { - Anemia: Hb } \\
<11 \mathrm{~g} / \mathrm{dL} \\
\text { - VCM }<72 \mathrm{fL} \\
-\mathrm{CVVE}> \\
14,5 \% \\
49-83,9 \text { meses } \\
\text { - Anemia: Hb } \\
<11,5 \mathrm{~g} / \mathrm{dL} \\
\text { - VCM }<75 \mathrm{fL} \\
\text { - CVVE }> \\
14,5 \% \\
12-83,9 \text { meses } \\
\text { - ADF: Hb } \\
\text { inferior } \\
\text { ao ponto } \\
\text { de corte, } \\
\text { associada a } \\
\text { VCM baixo } \\
\text { ou CVVE } \\
\text { elevado }\end{array}$ & - & $\begin{array}{l}\text { - Anemia: } \\
29,3 \\
\text { - VCM } \\
\text { baixo: } 13,0 \\
\text { - CVVE } \\
\text { elevado: 48,9 } \\
\text { - IST baixo: } \\
\text { 31,0 } \\
\text { - ADF: } 75,0\end{array}$ & - \\
\hline
\end{tabular}




\begin{tabular}{|c|c|c|c|c|c|c|c|c|}
\hline \multicolumn{9}{|c|}{ Quadro 1. continuação } \\
\hline $\begin{array}{l}\text { Autores, } \\
\text { ano }\end{array}$ & $\begin{array}{l}\text { Local de } \\
\text { estudo }\end{array}$ & $\begin{array}{l}\text { Faixa } \\
\text { etária }\end{array}$ & $\begin{array}{c}\text { Amostra } \\
\text { (perdas) }\end{array}$ & $\begin{array}{c}\text { Indicadores } \\
\text { bioquímicos e } \\
\text { técnicas de análises }\end{array}$ & $\begin{array}{l}\text { Pontos de } \\
\text { corte }\end{array}$ & $\begin{array}{l}\text { Variáveis } \\
\text { controladas } \\
\text { (modelo } \\
\text { final) }\end{array}$ & $\begin{array}{c}\text { Prevalências } \\
(\%)\end{array}$ & $\begin{array}{c}\text { Resultados } \\
\text { estatísticos } \\
\text { significantes }^{*}\end{array}$ \\
\hline $\begin{array}{l}\text { Vieira et al., } \\
2007^{27}\end{array}$ & $\begin{array}{l}\text { Recife (PE) } \\
34 \text { creches } \\
\text { municipais }\end{array}$ & $6-59$ & $\begin{array}{l}162 \\
(09)\end{array}$ & $\begin{array}{l}\text { - Hb: Cianometa- } \\
\text { hemoglobina } \\
\text { - FER: Ensaio } \\
\text { imunoenzimático } \\
\text { - FeS, CTLF: Método } \\
\text { colorimétrico } \\
\text { automático } \\
\text { - IST: Método } \\
\text { indireto a partir da } \\
\text { razão entre FeS e } \\
\text { CTLF X 100 } \\
\text { - PEL: hemato- } \\
\text { fluorimétrico }\end{array}$ & $\begin{array}{l}\text { - Anemia: Hb } \\
<11 \text { g/dL } \\
-\mathrm{FER}<12 \\
\mathrm{ng} / \mathrm{ml} \\
-\mathrm{FeS}<50 \\
\mu \mathrm{g} / \mathrm{dL} \\
-\mathrm{CTLF}>400 \\
\mu \mathrm{g} / \mathrm{dL} \\
-\mathrm{IST}<16 \% \\
-\mathrm{PEL}>40 \\
\mu \mathrm{mol} / \mathrm{mol} / \\
\text { heme }\end{array}$ & - & $\begin{array}{l}\text { - Anemia: } \\
\text { 55,6 } \\
\text { - FER baixa: } \\
30,8 \\
\text { - FeS baixo: } \\
62,2 \\
\text { - CTLF } \\
\text { elevado: } 8,0 \\
\text { - IST baixo: } \\
60,1 \\
\text { - PEL baixo: } \\
69,6\end{array}$ & $\begin{array}{l}\text { Hb, CTLF, PEL } \\
\text { - Faixa etária } \\
\text { da criança em } \\
\text { meses (6-24: } \mathrm{p} \\
<0,05 \text { quando } \\
\text { comparadas às } \\
\text { outras categorias: } \\
24-48 \text { e } \geq 48 \text { ) } \\
\text { Correlação } \\
\text { - Significativa } \\
\text { entre todos os } \\
\text { parâmetros ( }< \\
0,05 \text { ), a exceto da } \\
\text { Hb que apresentou } \\
\text { correlação apenas } \\
\text { com a PEL (p < } \\
0,05 \text { ) }\end{array}$ \\
\hline $\begin{array}{l}\text { Rocha et al., } \\
2008^{28}\end{array}$ & $\begin{array}{l}\text { Belo } \\
\text { Horizonte } \\
(\mathrm{MG}) \\
25 \text { creches } \\
\text { municipais } \\
\text { ou } \\
\text { conveniadas }\end{array}$ & $\begin{array}{l}7-74 \\
\text { meses }\end{array}$ & 402 & $\begin{array}{l}\text { - Hb: Fotômetro } \\
\text { portátil HemoCue }\end{array}$ & $\begin{array}{l}\text { 6-60 meses } \\
- \text { Anemia: Hb } \\
<11 \mathrm{~g} / \mathrm{dL} \\
>60 \text { meses } \\
- \text { Anemia: Hb } \\
<11,5 \mathrm{~g} / \mathrm{dL} \\
6-72 \text { meses } \\
\text { - Anemia } \\
\text { grave: } \mathrm{Hb}<7 \\
\text { g/dL } \\
- \text { Anemia } \\
\text { moderada: } \\
\mathrm{Hb} \text { entre } 7 \mathrm{e} \\
9 \text { g/dL }\end{array}$ & - & $\begin{array}{l}\text { - Anemia: } \\
28,8 \\
\text { - Anemia } \\
\text { grave: } 0,25 \\
\text { - Anemia } \\
\text { moderada: } \\
1,5\end{array}$ & $\begin{array}{l}\text { Anemia }(<60 \\
\text { meses) } \\
\text { - Faixa etária da } \\
\text { criança em meses } \\
(>6 \text { e } \leq 24: \text { OR = } \\
9,25 \text { e IC95\% } \% \\
3,74-23,31 ;>24 \\
\text { e } \leq 48: \text { OR }=1,31 \\
\text { e IC95\% }=0,69- \\
2,49 ;>48 \text { e }<60 \text { : } \\
\text { OR = } 1) \\
\text { - Escore-Z de } \\
\text { estatura/idade (< } \\
\text {-2: OR = 1,31 e } \\
\text { IC95\% = 0,32- } \\
5,02 ;-2 \mid--1: \text { OR } \\
=2,05 \text { e IC95\% }= \\
1,09-3,97 ; \geq-1: \text { OR } \\
=1)\end{array}$ \\
\hline
\end{tabular}

continua

As prevalências de deficiência de zinco no cabelo e da atividade de FA foram de $61,9 \%$ e $40,1 \%$, respectivamente ${ }^{20}$. A deficiência de zinco no soro foi de $16,2 \%$ em um dos estudos ${ }^{34}$ e de $13,8 \%$ no outro ${ }^{36}$. A deficiência de vitamina A variou de $7,0 \%{ }^{23}$ a $23,3 \%{ }^{36}$, com prevalência média ponderada pelos respectivos tamanhos amostrais de $12,5 \%$ (amplitude: $23,3-7,0=16,3$ ), que cor- responde a 117 crianças com a carência de um total de 937. As prevalências de anemia, por sua vez, apresentaram oscilação entre $10,4 \%{ }^{17} \mathrm{em}$ crianças de creches municipais de Minas Gerais, Sudeste do Brasil, e $92,4 \%{ }^{25}$ em crianças de São Paulo. As prevalências de ADF estiveram entre $51,3 \%{ }^{21}$ e $75,0 \%{ }^{26}$. Considerando as prevalências de anemia dos estudos sistematizados, obtém-se 


\begin{tabular}{|c|c|c|c|c|c|c|c|c|c|}
\hline \multirow{4}{*}{ 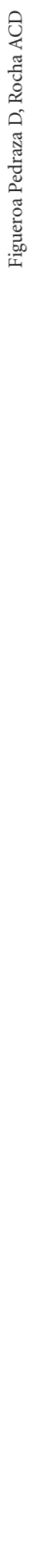 } & Quadro 1.co & ntinuação & 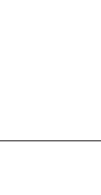 & 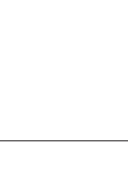 & 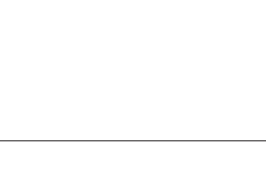 & 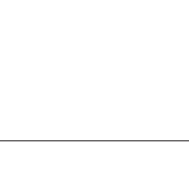 & - & & \\
\hline & $\begin{array}{l}\text { Autores, } \\
\text { ano }\end{array}$ & $\begin{array}{l}\text { Local de } \\
\text { estudo }\end{array}$ & $\begin{array}{l}\text { Faixa } \\
\text { etária }\end{array}$ & $\begin{array}{r}\text { Amostra } \\
\text { (perdas) }\end{array}$ & $\begin{array}{c}\text { Indicadores } \\
\text { bioquímicos e } \\
\text { técnicas de análises }\end{array}$ & $\begin{array}{l}\text { Pontos de } \\
\text { corte }\end{array}$ & $\begin{array}{c}\text { Variáveis } \\
\text { controladas } \\
\text { (modelo } \\
\text { final) }\end{array}$ & $\begin{array}{c}\text { Prevalências } \\
(\%)\end{array}$ & $\begin{array}{c}\text { Resultados } \\
\text { estatísticos } \\
\text { significantes }^{*}\end{array}$ \\
\hline & $\begin{array}{l}\text { Camillo et } \\
\text { al., } 2008^{29}\end{array}$ & $\begin{array}{l}\text { Guaxupé } \\
\text { (MG) } \\
3 \text { creches } \\
\text { públicas/ } \\
\text { filantrópicas }\end{array}$ & $\begin{array}{l}6-72 \\
\text { meses }\end{array}$ & $\begin{array}{l}250 \\
(39)\end{array}$ & $\begin{array}{l}\text { - Hb: Método } \\
\text { semiautomatizado } \\
\text { - FeS: Método } \\
\text { Ferrozine } \\
\text { - CTLF: } \\
\text { Espectrofotometria } \\
\text { de adsorção de } \\
\text { carbonato de } \\
\text { magnésio em sistema } \\
\text { semiautomático } \\
\text { Bioplus } \\
\text { - IST: Método } \\
\text { indireto a partir da } \\
\text { razão entre FeS e } \\
\text { CTLF X } 100\end{array}$ & $\begin{array}{l}\text { 6-60 meses } \\
\text { - Anemia: Hb } \\
<11 \text { g/dL } \\
>60 \text { meses } \\
\text { - Anemia: Hb } \\
<11,5 \mathrm{~g} / \mathrm{dL} \\
-\mathrm{FeS}<56 \\
\mu \mathrm{g} / \mathrm{dL} \\
-\mathrm{CTLF}>400 \\
\mu \mathrm{g} / \mathrm{dL} \\
-\mathrm{IST}<16 \%\end{array}$ & - & $\begin{array}{l}\text { - Anemia: } \\
\text { 16,1 } \\
\text { - FeS baixo: } \\
45 \\
\text { - CTLF } \\
\text { elevado: } 37,9 \\
\text { - IST baixo: } \\
43,1\end{array}$ & $\begin{array}{l}\text { Hb, FeS, IST } \\
\text { - Faixa etária } \\
\text { da criança em } \\
\text { meses (6-36: } p \\
<0,05 \text { quando } \\
\text { comparadas às } \\
\text { outras categorias: } \\
\text { 36-60 e 60-72) } \\
\text { CTLF } \\
\text { - Faixa etária } \\
\text { da criança em } \\
\text { meses (60-72: p } \\
<0,05 \text { quando } \\
\text { comparadas às } \\
\text { outras categorias: } \\
\text { 6-36 e 36-60) }\end{array}$ \\
\hline & $\begin{array}{l}\text { Costa et al., } \\
2009^{30}\end{array}$ & $\begin{array}{l}\text { São Paulo } \\
\text { (SP) } \\
6 \text { creches } \\
\text { municipais }\end{array}$ & $\begin{array}{l}24-60 \\
\text { meses }\end{array}$ & $\begin{array}{l}476 \\
(17)\end{array}$ & $\begin{array}{l}\text { - Hb: Fotômetro } \\
\text { portátil HemoCue }\end{array}$ & $\begin{array}{l}\text { - Anemia: } \mathrm{Hb} \\
<11 \mathrm{~g} / \mathrm{dL} \\
\text { - Anemia } \\
\text { grave: } \mathrm{Hb}< \\
9,5 \mathrm{~g} / \mathrm{dL}\end{array}$ & - & $\begin{array}{l}\text { - Anemia: } \\
20,9 \\
\text { - Anemia } \\
\text { grave: } 4,4\end{array}$ & $\begin{array}{l}\text { Não foram } \\
\text { encontrados } \\
\text { resultados } \\
\text { estatísticos } \\
\text { significantes } \\
\text { para as variáveis } \\
\text { de estudo: a) } \\
\text { da criança } \\
\text { (faixa etária, } \\
\text { sexo, Escore-Z } \\
\text { de estatura/ } \\
\text { idade, Escore-Z } \\
\text { de peso/idade, } \\
\text { Escore-Z de peso/ } \\
\text { estatura); b) da } \\
\text { família (número } \\
\text { de moradores, } \\
\text { número de irmãos, } \\
\text { idade da mãe, } \\
\text { escolaridade } \\
\text { da mãe, renda } \\
\text { materna) }\end{array}$ \\
\hline
\end{tabular}

continua

uma prevalência média ponderada pelos respectivos tamanhos amostrais de 42,7\% (amplitude: $92,4-10,4=82,0)$, que corresponde a 2.357 crianças anêmicas de um total de 5.522 .

Análises multivariadas com o controle para variáveis de confundimento foram conduzidas em seis ${ }^{18,21,24,25,31,35}$ dos estudos revisados. As análises sistematizadas destacam que crianças de menor idade $\mathrm{e}^{18,21,25,31}$ e de pior condição socioeconômica ${ }^{18,24,31,35}$ representaram as principais condições explicativas para a ocorrência de anemia. Outras variáveis de interesse também foram cita- 


\begin{tabular}{|c|c|c|c|c|c|c|c|c|}
\hline \multicolumn{9}{|c|}{ Quadro 1. continuação } \\
\hline $\begin{array}{l}\text { Autores, } \\
\text { ano }\end{array}$ & $\begin{array}{l}\text { Local de } \\
\text { estudo }\end{array}$ & $\begin{array}{l}\text { Faixa } \\
\text { etária }\end{array}$ & $\begin{array}{c}\text { Amostra } \\
\text { (perdas) }\end{array}$ & $\begin{array}{c}\text { Indicadores } \\
\text { bioquímicos e } \\
\text { técnicas de análises }\end{array}$ & $\begin{array}{l}\text { Pontos de } \\
\text { corte }\end{array}$ & $\begin{array}{c}\text { Variáveis } \\
\text { controladas } \\
\text { (modelo } \\
\text { final) }\end{array}$ & $\begin{array}{c}\text { Prevalências } \\
(\%)\end{array}$ & $\begin{array}{c}\text { Resultados } \\
\text { estatísticos } \\
\text { significantes }^{*}\end{array}$ \\
\hline $\begin{array}{l}\text { Kostantyner } \\
\text { et al., } 2009^{31}\end{array}$ & $\begin{array}{l}\text { São Paulo } \\
\text { (SP) } \\
31 \text { creches } \\
\text { públicas e } \\
\text { filantrópicas }\end{array}$ & $\begin{array}{l}4-29 \\
\text { meses }\end{array}$ & $\begin{array}{l}498 \\
(16)\end{array}$ & $\begin{array}{l}\text { - Hb: Fotômetro } \\
\text { portátil HemoCue }\end{array}$ & $\begin{array}{l}\text { - Anemia: Hb } \\
<11 \text { g/dL }\end{array}$ & $\begin{array}{l}\text { - Duração } \\
\text { do } \\
\text { aleitamento } \\
\text { exclusivo } \\
\text { - Prematuri- } \\
\text { dade } \\
\text { - Idade } \\
\text { materna } \\
\text { - Renda per } \\
\text { capita } \\
\text { - Tempo de } \\
\text { creche } \\
\text { - Peso ao } \\
\text { nascer } \\
\text { - Idade da } \\
\text { criança } \\
\text { - Irmãos< } \\
5 \text { anos de } \\
\text { idade } \\
\text { - Evolução } \\
\text { ponderal em } \\
\text { relação ao } \\
\text { nascimento }\end{array}$ & $\begin{array}{l}\text { - Anemia: } \\
43,6 \\
\\
\\
\\
\end{array}$ & 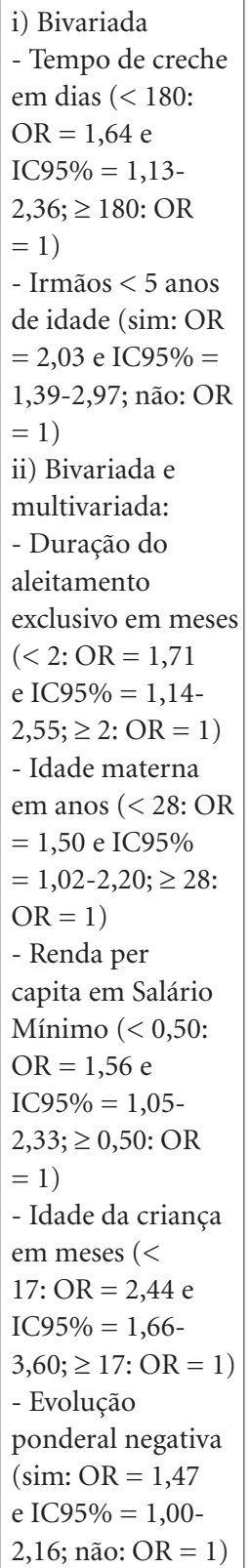 \\
\hline
\end{tabular}

continua

das em vários estudos como associadas à anemia, considerando tanto as análises bivariadas quanto as multivariadas, indicando crianças comprome- tidas do ponto de vista antropométrico ${ }^{19,24,28,29}$ e o menor tempo de institucionalização $0^{19,25,31,35}$ como condições de risco. 


\begin{tabular}{|c|c|c|c|c|c|c|c|c|}
\hline \multirow{3}{*}{ 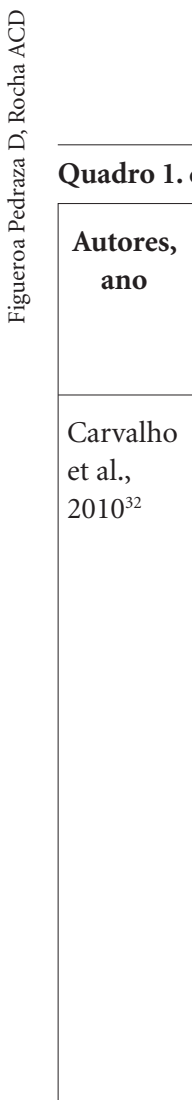 } & continuação & 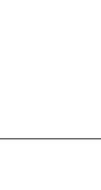 & 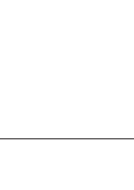 & 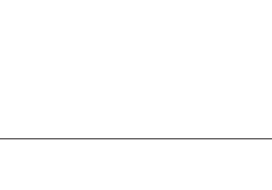 & 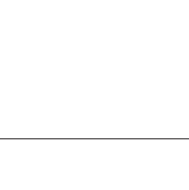 & ${ }_{-}$ & & \\
\hline & $\begin{array}{c}\text { Local de } \\
\text { estudo }\end{array}$ & $\begin{array}{l}\text { Faixa } \\
\text { etária }\end{array}$ & $\begin{array}{l}\text { Amostra } \\
\text { (perdas) }\end{array}$ & $\begin{array}{c}\text { Indicadores } \\
\text { bioquímicos e } \\
\text { técnicas de análises }\end{array}$ & $\begin{array}{l}\text { Pontos de } \\
\text { corte }\end{array}$ & $\begin{array}{c}\text { Variáveis } \\
\text { controladas } \\
\text { (modelo } \\
\text { final) }\end{array}$ & $\begin{array}{c}\text { Prevalências } \\
(\%)\end{array}$ & $\begin{array}{c}\text { Resultados } \\
\text { estatísticos } \\
\text { significantes }^{*}\end{array}$ \\
\hline & $\begin{array}{l}\text { Recife }(\mathrm{PE}) \\
13 \text { creches } \\
\text { municipais }\end{array}$ & $\begin{array}{l}6-30 \\
\text { meses }\end{array}$ & $\begin{array}{l}335 \\
(34)\end{array}$ & $\begin{array}{l}\text { - Hb, VCM: } \\
\text { Contador } \\
\text { automático de } \\
\text { células Pentra } \\
\text { - FER: } \\
\text { Quimiluminescência } \\
\text { - IST: } \\
\text { Espectrofotometria } \\
\text { - RT: Ensaio } \\
\text { imunoenzimático } \\
\text { ELISA }\end{array}$ & $\begin{array}{l}\text { - Anemia: Hb } \\
<11 \text { g/dL } \\
\text { - Anemia } \\
\text { moderada/ } \\
\text { grave: } \mathrm{Hb}<9 \\
\text { g/dL } \\
\text { - VCM }< \\
77 \mathrm{fL} \\
\text { - FER < } 12 \\
\mu \mathrm{g} / \mathrm{L} \\
\text { - IST }<16 \% \\
\text { - RT }>8,3 \\
\mathrm{mg} / \mathrm{L} \\
-\mathrm{ADF}: \mathrm{Hb} \\
<11 \mathrm{~g} / \mathrm{dL}, \\
\mathrm{RT}>8,3 \mathrm{mg} / \mathrm{L}, \\
\mathrm{FER}<12 \\
\mu \mathrm{g} / \mathrm{L}\end{array}$ & - & $\begin{array}{l}\text { - Anemia: } \\
\text { 92,4 } \\
\text { - Anemia } \\
\text { moderada/ } \\
\text { grave: } 28,9 \\
\text { - FER baixa: } \\
51,5 \\
\text { - ADF: } 58,1\end{array}$ & $\begin{array}{l}\text { Hb, VCM, RT } \\
\text { - Faixa etária da } \\
\text { criança em meses: } \\
\text { p }<0,05 \text { para } \mathrm{Hb} \\
\text { e VCM e } \mathrm{p}<0,01 \\
\text { para RT quando } \\
\text { comparadas as } \\
\text { categorias: } 6-11 \text {, } \\
\text { 12-17, 18-23 e } \\
24-30 \\
\text { FER } \\
\text { - Proteína } \\
\text { C-Reativa: } p< \\
\text { 0,001 com valores } \\
\text { maiores quando } \\
\text { Proteína C-Reativa } \\
\text { aumentada }\end{array}$ \\
\hline $\begin{array}{l}\text { Azevedo } \\
\text { et al., } \\
2010^{33}\end{array}$ & $\begin{array}{l}\text { Recife }(\mathrm{PE}) \\
18 \text { creches } \\
\text { públicas }\end{array}$ & $\begin{array}{l}24-60 \\
\text { meses }\end{array}$ & $\begin{array}{l}344 \\
(84)\end{array}$ & $\begin{array}{l}\text { - RS: Cromatografia } \\
\text { líquida de alta } \\
\text { resolução }\end{array}$ & $\begin{array}{l}-\mathrm{RS}<0,70 \\
\mu \mathrm{mol} / \mathrm{L}\end{array}$ & - & - DVA: 7,7 & $\begin{array}{l}\text { Não foram } \\
\text { encontrados } \\
\text { resultados } \\
\text { estatísticos } \\
\text { significantes para } \\
\text { as variáveis de } \\
\text { estudo: sexo, idade } \\
\text { e ingestão dietética } \\
\text { de vitamina A }\end{array}$ \\
\hline $\begin{array}{l}\text { Figueroa } \\
\text { Pedraza } \\
\text { et al., } \\
2011^{34}\end{array}$ & $\begin{array}{l}\text { Paraíba } \\
14 \text { creches } \\
\text { estaduais }\end{array}$ & $\begin{array}{l}6-72 \\
\text { meses }\end{array}$ & $\begin{array}{l}256 \\
(21)\end{array}$ & $\begin{array}{l}\text { - Zn Sérico: } \\
\text { Espectrofotometria } \\
\text { de absorção } \\
\text { atômica de chama }\end{array}$ & $\begin{array}{l}- \text { Zn Sérico < } \\
65 \mu \mathrm{g} / \mathrm{dL}\end{array}$ & - & $\begin{array}{l}\text { - Déficit de } \\
\text { Zn sérico: } \\
16,2\end{array}$ & $\begin{array}{l}\text { - Estado } \\
\text { nutricional } \\
\text { materno: } \mathrm{p}= \\
0,016 \text { quando } \\
\text { comparadas } \\
\text { as categorias: } \\
\text { obesidade, } \\
\text { sobrepeso, } \\
\text { normalidade e } \\
\text { baixo peso }\end{array}$ \\
\hline
\end{tabular}

continua

\section{Discussão}

O presente trabalho sintetiza estudos observacionais, com crianças brasileiras assistidas em creches, que abordam o diagnóstico bioquímico do estado nutricional dos micronutrientes (ferro, vitamina $\mathrm{A}$, zinco) mais importantes no cresci- mento linear. Foram incluídos artigos selecionados a partir de amostras aleatórias representativas, garantindo a aplicabilidade dos resultados obtidos.

Os resultados do presente estudo mostram a existência de experiências isoladas relacionadas com a avaliação bioquímica do estado nutricional 


\begin{tabular}{|c|c|c|c|c|c|c|c|c|}
\hline \multicolumn{9}{|c|}{ Quadro 1. continuação } \\
\hline $\begin{array}{c}\text { Autores, } \\
\text { ano }\end{array}$ & $\begin{array}{l}\text { Local de } \\
\text { estudo }\end{array}$ & $\begin{array}{l}\text { Faixa } \\
\text { etária }\end{array}$ & $\begin{array}{c}\text { Amostra } \\
\text { (perdas) }\end{array}$ & $\begin{array}{c}\text { Indicadores } \\
\text { bioquímicos e } \\
\text { técnicas de análises }\end{array}$ & $\begin{array}{l}\text { Pontos de } \\
\text { corte }\end{array}$ & $\begin{array}{l}\text { Variáveis } \\
\text { controladas } \\
\text { (modelo } \\
\text { final) }\end{array}$ & $\begin{array}{c}\text { Prevalências } \\
(\%)\end{array}$ & $\begin{array}{l}\text { Resultados } \\
\text { estatísticos } \\
\text { significantes }^{*}\end{array}$ \\
\hline $\begin{array}{l}\text { Rodrigues } \\
\text { et al., } \\
2011^{35}\end{array}$ & $\begin{array}{l}\text { Cascavel } \\
(\mathrm{PR}) \\
25 \text { creches } \\
\text { municipais }\end{array}$ & $\begin{array}{l}6-24 \\
\text { meses }\end{array}$ & $\begin{array}{l}280 \\
(24)\end{array}$ & $\begin{array}{l}\text { Hb: Método } \\
\text { automatizado } \\
\text { Lauril Sulfato de } \\
\text { Sódio } \\
\text { FeS: Calorimetria } \\
\text { VCM: Cálculo } \\
\text { mediante o valor de } \\
\text { eritrócitos e Hb } \\
\text { RT: Nefelometria }\end{array}$ & $\begin{array}{l}-\mathrm{FeS}<50 \\
\mu \mathrm{g} / \mathrm{dL} \\
-\mathrm{VCM}< \\
70 \mathrm{mcg} 3 \\
-\mathrm{RT}>360 \\
\mathrm{mg} / \mathrm{dL}\end{array}$ & $\begin{array}{l}\text { Escolaridade } \\
\text { dos pais } \\
\text { - Renda } \\
\text { familiar } \\
\text { - Doenças } \\
\text { frequentes } \\
\text { na família } \\
\text { - Condições } \\
\text { de moradia } \\
\text { - Número } \\
\text { de } \\
\text { residentes } \\
\text { no } \\
\text { domicílio } \\
\text { - } \\
\text { Saneamento } \\
\text { - Tempo de } \\
\text { creche }\end{array}$ & $\begin{array}{l}\text { - Anemia: } \\
29,7 \\
\text { - FeS baixo: } \\
77,7 \\
\text { - VCM } \\
\text { baixo: } 28,9 \\
\text { - RT baixo: } \\
14,1\end{array}$ & 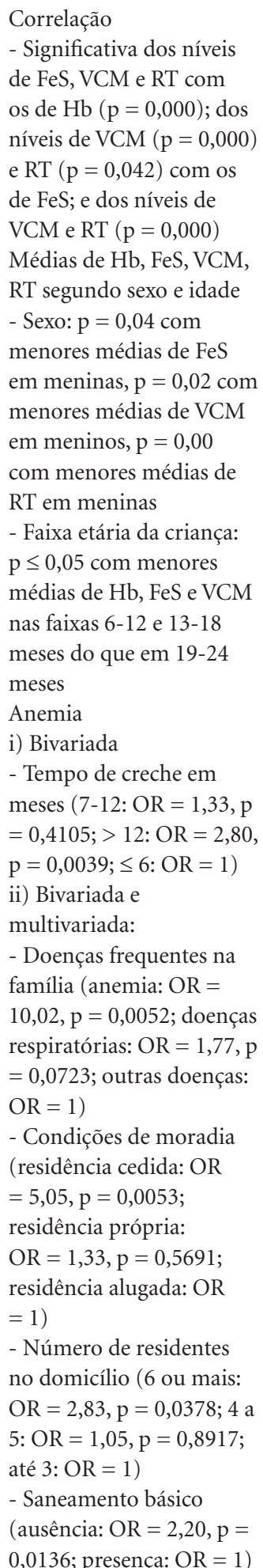 \\
\hline
\end{tabular}




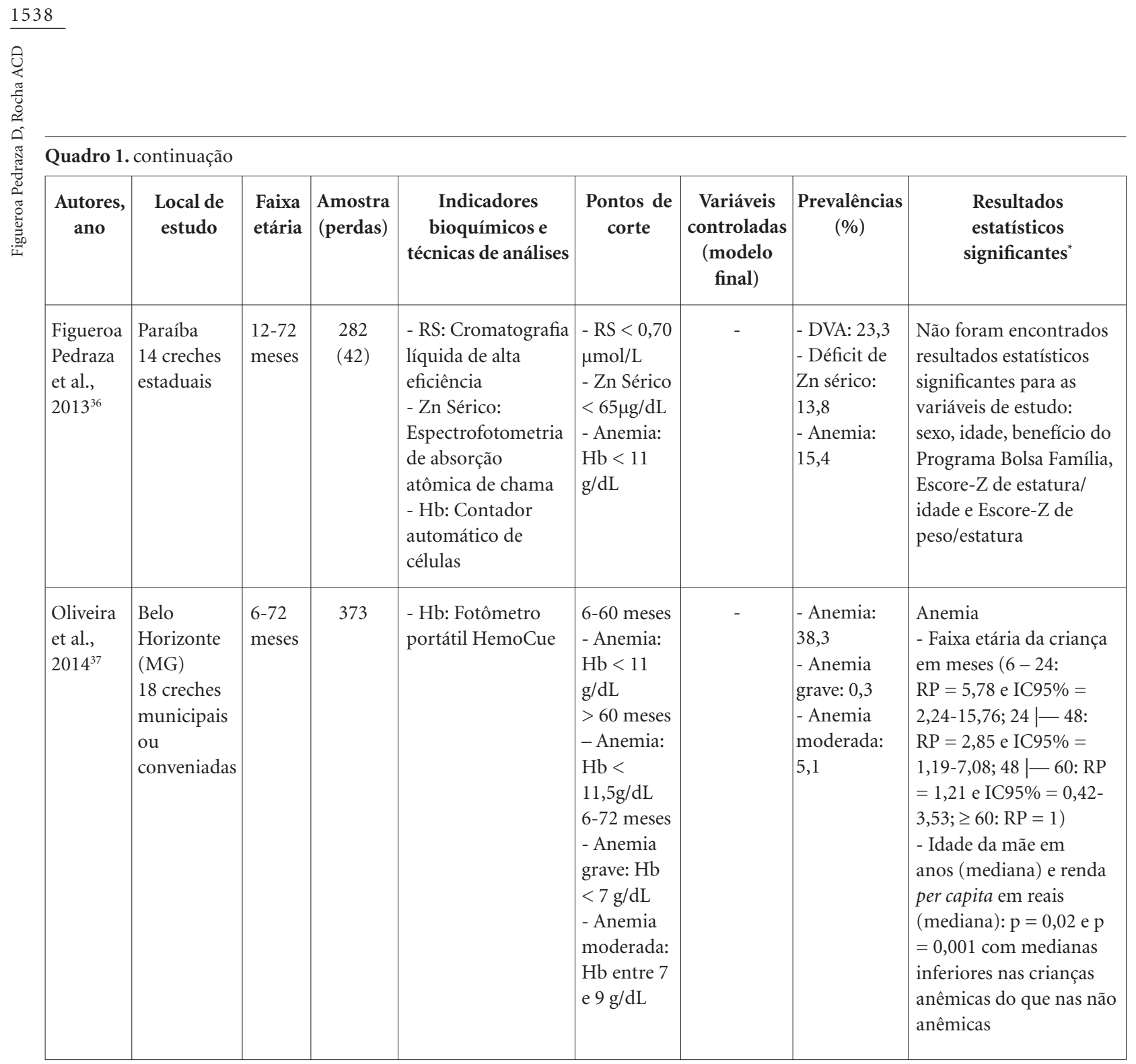

DVA: Deficiência de Vitamina A; RS: Retinol Sérico; Ht: Hematócrito; FER: Ferritina Sérica; IST: Índice de Saturação de Transferrina; PEL: Proto-porfirina Eritrocitária Livre; VCM: Volume Corpuscular Médio; CVVE: Coeficiente de Variação do Volume Eritrocitário; CTLF: Capacidade Total de Ligação de Ferro; FA: Fosfatase Alcalina Sérica; Zn Cabelo: Zinco no Cabelo; ADF: Anemia por Deficiência de Ferro; RT: Receptores de Transferrina; FeS: Ferro Sérico; Zn Sérico: Zinco Sérico; NR: Não relatado; -: Não verificado; RP: Razão de Prevalências; OR: Razão de Chances; IC95\%: Intervalo de Confiança de 95\%; ${ }^{*}$ Nos casos de "bivariada e multivariada", os valores relatados correspondem aos das análises multivariada; +Bloco 1: faixa etária, sexo, peso ao nascer, idade gestacional, hospitalização, risco nutricional / Bloco 2: idade da mãe, posição entre os irmãos, intervalo interpartal anterior, intervalo interpartal posterior, irmãos < 5 anos / Bloco 3: amamentação materna exclusiva, amamentação materna / Bloco 4: renda per capita, nível de pobreza.

de ferro, vitamina A e zinco envolvendo crianças assistidas em creches. Esse resultado pode estar relacionado à concentração da produção científica no Sudeste, fato esse anteriormente apontado por outros pesquisadores, tanto na área de nutrição ${ }^{38}$ quanto em outras temáticas sobre a saúde das crianças".

Por outro lado, a escassez absoluta e relativa (no contexto geográfico e socioeconômico) de estudos, em especial sobre o estado nutricional de zinco e vitamina $\mathrm{A}$, por meio de indicadores bioquímicos, pode estar relacionada às dificuldades implícitas na coleta de sangue em crianças, assim como às dificuldades técnicas e aos custos relacionados às análises ${ }^{9,39,40}$. Ainda, esses fatores podem explicar o predomínio de estudos de cunho transversal nesta revisão. Nesse sentido, há que destacar a importância do desenvolvimento de estudos longitudinais para explorar melhor a relação entre a creche e o estado nutricional de crianças.

A escassez de artigos sobre o estado nutricional de zinco, além da diversidade de indicadores e de técnicas usadas nos estudos que enfocaram o micronutriente, inviabiliza qualquer tentativa de síntese sobre a magnitude e a etiologia da defi- 
ciência desse metal nas crianças institucionalizadas em creches. Esse resultado tem implicações muito importantes, pois indica uma lacuna no conhecimento que precisa ser compensada. Inexistem pesquisas de âmbito nacional e de sistematização sobre a deficiência de zinco no Brasil.

As dificuldades técnicas relacionadas à obtenção da amostra, análises de laboratório e interpretação dos resultados, são apontadas como justificativas para a carência de estudos sobre o estado nutricional relativo ao zinco, tanto no Brasil quanto em outros países ${ }^{40}$. Assim, destaca-se a necessidade de pesquisas direcionadas ao desenvolvimento de técnicas de avaliação bioquímica de menores custos e que precisem de menor quantidade de sangue ${ }^{9}$, essencial para uma caracterização mais precisa da magnitude e distribuição da deficiência de zinco, estimada como um potencial problema de saúde pública em diversos países em desenvolvimento ${ }^{40}$. Nesse sentido, adverte-se que a concentração de zinco no soro ou plasma constitui na atualidade o melhor indicador do risco de sua deficiência nas populações ${ }^{40}$, o qual foi utilizado apenas em dois estudos ${ }^{34,36}$.

Estudos sistematizados sobre a deficiência de vitamina A apontam claramente prevalências preocupantes nas crianças brasileiras ${ }^{41-43}$, que convergem com as reportadas nos estudos da presente revisão contextualizando as crianças que frequentam creches. A prevalência média ponderada pelos respectivos tamanhos amostrais de deficiência de vitamina $\mathrm{A}$, estimada para o conjunto de crianças dos estudos desta revisão, de 12,5\% (amplitude: 23,3 - 7,0 = 16,3), insere-se na classificação epidemiológica da Organização Mundial da Saúde como um problema de saúde pública de grau moderado ${ }^{42}$. Essa classificação coincide com a que seria estabelecida para as crianças brasileiras considerando a prevalência de $17,4 \%$ encontrada na Pesquisa Nacional de Demografia e Saúde de $2006^{15}$. Estimativas da Organização Mundial da Saúde indicam que 122 países apresentam deficiência de vitamina A com significado de saúde pública em crianças pré-escolares ${ }^{42}$. Apesar de prevalências mais elevadas em outros países, principalmente da África e do Leste da Ásia, no Brasil a deficiência de vitamina A ainda apresenta relevância epidemiológica, principalmente nas regiões Sudeste e Nordeste ${ }^{41,42}$.

Embora a escassez de estudos e de resultados inviabilize a sistematização do conhecimento sobre a etiologia da deficiência de vitamina $\mathrm{A}$, há que ressaltar a possível contribuição da enfermidade por doenças infecciosas ${ }^{42}$, que apresenta alto índice no grupo de crianças assistidas em creches ${ }^{4,6}$.
Episódios de infecções graves ou prolongados podem afetar os estoques hepáticos de vitamina A como consequência de alguns fatores, entre os quais a redução da ingestão alimentar e problemas relacionados à utilização biológica ${ }^{44}$. Por sua vez, a presença de infecção subclínica pode acarretar deficiência de vitamina A por efeito de uma diminuição da proteína de transporte de retinol. Essas circunstâncias apontam para a importância de se controlar o efeito da inflamação subclínica nos marcadores bioquímicos do estado nutricional de vitamina $\mathrm{A}^{44,45}$, limitação que, em geral, pode ser atribuída aos estudos sistematizados, uma vez que não consideraram esse procedimento. Entretanto, confirmando as indicações da literatura, todos os trabalhos utilizaram as concentrações de retinol sérico, considerado o principal indicador do estado nutricional de vitamina $\mathrm{A}^{16}$.

Em relação ao estado nutricional de ferro, com base nas altas prevalências de anemia e de $\mathrm{ADF}$, pode-se inferir que a deficiência de ferro em crianças assistidas em creches contribui, também, para aquele que representa, em termos de magnitude, a principal carência nutricional das crianças brasileiras ${ }^{46,47}$. Considerando a prevalência média ponderada pelos respectivos tamanhos amostrais de anemia de $42,7 \%$ (amplitude: 92,4 - 10,4 = 82,0) pode-se assumir um problema de saúde pública severo, segundo a classificação epidemiológica da Organização Mundial da Saúde ${ }^{48}$. Esse resultado, embora um pouco discrepante da prevalência encontrada pela Pesquisa Nacional de Demografia e Saúde de $2006^{15}$ (20,9\%), assemelha-se ao de outros estudos de base populacional $^{49-51}$ e à proporção $(39,0 \%)$ nos países em desenvolvimento, entre os quais o Brasil, apresentando a segunda maior prevalência da América Latina $^{46}$.

A pobre condição socioeconômica das famílias com crianças assistidas em creches públicas e as condições de convívio aos quais essas crianças estão expostas, como a aglomeração e a higiene, são fatores que se entrelaçam podendo conduzir à baixa ingestão dietética de ferro biodisponível e/ou à maior incidência de parasitoses que produzem perda sanguínea ${ }^{6,46}$, explicações cabíveis em relação à maior proporção de anemia entre as crianças assistidas em creches do que nas crianças do Brasil em geral.

Por outro lado, indica-se que a persistência de prevalências elevadas de anemia nas crianças brasileiras associa-se a mudanças no consumo alimentar, particularmente à elevação do consumo de leite que substitui outras fontes alimentares mais ricas em ferro ou limita a absorção de 
ferro ${ }^{47}$. Assim, a adoção de práticas alimentares adequadas no primeiro ano de vida é relevante na prevenção da deficiência de ferro, principalmente a alimentação complementar com o de alta biodisponibilidade e o consumo de suplementos em dose profilática e/ou de alimentos fortificados ${ }^{52}$. Tais recomendações são importantes e devem ser consideradas na alimentação das crianças, sobretudo nas creches com berçário.

Do ponto de vista metodológico, é necessário ressaltar que a variedade constatada nas técnicas de análise do estado nutricional de ferro pode limitar a obtenção de resultados não conflitantes. Essa diversidade pode estar relacionada à necessidade de avaliar os diferentes compartimentos de distribuição do ferro. Nesse sentido, é importante destacar que a $\mathrm{Hb}$, parâmetro utilizado na totalidade dos estudos revisados, justifica-se por suas vantagens relacionadas ao baixo custo e por estar universalmente disponível, entretanto é um indicador de baixas sensibilidade e especificidade, reforçando a importância de sua utilização com outros indicadores ${ }^{53}$, o que aconteceu em um número limitado dos estudos sistematizados. Além disso, há que enfatizar a influência que a técnica de coleta do sangue e que os tipos de amostra de sangue (venosa, capilar) pode ter nos resultados das análises, destacando que hemoglobina em sangue capilar medida pelo HemoCue é adequada como estimativa da prevalência de anemia (comparando à hemoglobina em sangue venosa medida por espectrofotômetro automatizado) ${ }^{54}$.

Os resultados do presente trabalho indicam a influência da idade da criança e da situação socioeconômica na etiopatogenia da anemia. Apesar das limitações do presente estudo, devido à não utilização de indicadores de consumo alimentar e da situação de saúde/morbidade, esses resultados situam, novamente, influenciado por variações decorrentes de características como a idade e a situação socioeconômica, a ingestão de ferro biodisponível e/ou as perdas sanguíneas devido a parasitas como possíveis explicações ${ }^{46}$. A maior prevalência de anemia nas crianças de menor faixa etária e de maior vulnerabilidade socioeconômica entre as menores de cinco anos tem sido igualmente apontada em outros cenários epidemiológicos ${ }^{55,56}$, no âmbito nacional ${ }^{15} \mathrm{e}$ em outras revisões ${ }^{57,58}$.

Abordando fatores associados à ocorrência da anemia baseada em estudos populacionais, trabalho de revisão, além de mostrar que a idade da criança representa o principal fator biológico associado a esse agravo, concluiu que a situação socioeconômica mostra-se relevante nos países em desenvolvimento ${ }^{57}$. Assim, apesar da garantia de acesso à alimentação nas creches ${ }^{6,12}$, as crianças desse cenário apresentam similar determinação da anemia em relação ao âmbito nacional e em outros cenários. A maior carga de enteroparasitoses entre as crianças que frequentam creches $^{4} \mathrm{e}$ indícios sobre baixos índices de aceitação da alimentação escolar ${ }^{59}$, podem ser fatores essencialmente envolvidos nessa problemática e precisam, portanto, de maior atenção.

Outros fatores que se mostraram associados ao estado nutricional de ferro foram o perfil antropométrico e o tempo de institucionalização. Apesar de os estudos de base longitudinal mostrarem influência positiva da frequência à creche na redução da anemia ${ }^{5}$ e a sistematização da associação entre a anemia e o déficit de estatura ${ }^{9}$, considera-se a necessidade de maior quantidade de pesquisas brasileiras de base populacional que possibilitem confirmar esses resultados.

Os resultados apresentados permitem a composição de um panorama preliminar de altas prevalências de anemia e de deficiência de vitamina A, com contribuição importante nas respectivas taxas da população de crianças brasileiras. Esses resultados são constatados em situações positivas relacionadas à existência de programas nacionais de suplementação de vitamina A e de ferro, o que indica a necessidade de esforços direcionados, também, à avaliação de impacto de tais programas. A prevenção das deficiências de ferro, vitamina A e zinco é essencial para melhorar a sobrevivência, a morbimortalidade, o crescimento e o desenvolvimento das crianças. Nesse contexto, as condições associadas ao maior adoecimento por doenças infecciosas nas crianças assistidas em creches devem ser particularmente considerados.

Conclui-se, que a anemia, a deficiência de vitamina $\mathrm{A}$ e a deficiência de zinco constituem graves problemas de saúde pública que permanecem com incertezas quanto ao perfil epidemiológico das crianças assistidas em creches. Os estudos sobre as prevalências da deficiência de zinco nas crianças institucionalizadas em creches são escassos, o que inviabiliza qualquer tentativa de síntese sobre a sua magnitude e etiologia. Os estudos sobre o estado nutricional de vitamina $\mathrm{A}$ também são escassos, porém, com maiores semelhanças nos métodos diagnósticos. Para o diagnóstico da anemia, os métodos adotados pelos pesquisadores apresentam-se heterogêneos. Os resultados sugerem altas prevalências de anemia e de deficiência de vitamina A entre as crianças brasileiras assistidas em creches, e perspectivas etiológicas centradas nas doenças infecciosas. 


\section{Considerações finais}

As creches são uma realidade na vida de grande parcela das crianças brasileiras, onde permanecem por um longo período de tempo, cinco dias por semana. É conhecida a determinação multicausal das carências nutricionais, com condicionantes biológicos e sociais relacionados ao atendimento das necessidades básicas como alimentação, saneamento, educação e saúde. Assim, é fundamental precisar a magnitude desses agravos e o entendimento sobre os fatores de risco, inclusive em grupos ou populações específicas, como subsídio para a adoção de medidas eficazes de prevenção e controle. A vulnerabilidade biológica e social, bem como as particularidades relacionadas com a institucionalização, faz das crianças assistidas em creches um grupo populacional de interesse.
Há que ressaltar que nenhum dos estudos revisados considerou todos os três micronutrientes de interesse. Esse aspecto torna-se relevante uma vez que o crescimento representa um processo altamente dependente de vitamina A, zinco e ferro, cujas carências normalmente não ocorrem isoladamente. Nesse contexto, fatores como o custo das técnicas de avaliação bioquímica e a necessidade de grandes quantidades de sangue devem ser considerados limitantes no diagnóstico do estado nutricional de micronutrientes de grupos populacionais e, portanto, reparados.

Face à dificuldade de implementação de grandes pesquisas nacionais, a alternativa de estudos multicêntricos, aliada a investigações pontuais, mas comparáveis, poderia ser adotada como estratégia para uma melhor caracterização etiopatogênica, morfofuncional e diagnóstica das deficiências de micronutrientes, bem como da repercussão dessas carências no crescimento e no desenvolvimento infantil.

\section{Colaboradores}

D Figueroa Pedraza concebeu o objetivo e participou da busca bibliográfica, interpretação dos resultados, redação e revisão do artigo; ACD Rocha participou da busca bibliográfica, interpretação dos resultados, redação e revisão do artigo. 


\section{Referências}

1. Brasil. Ministério da Educação(MS). Secretaria de Educação Básica. Parâmetros nacionais de qualidade para a educação infantil. Brasília: MS; 2006.

2. Zöllner CC, Fisberg RM. Estado nutricional e sua relação com fatores biológicos, sociais e demográficos de crianças assistidas por creches da Prefeitura do Município de São Paulo. Rev Bras Saude Mater Infant 2006; 6(3):319-328.

3. Goulart RMM, Banduk MLS, Taddei JAAC. Uma revisão das ações de nutrição e do papel do nutricionista em creches. Rev Nutr 2010; 23(4):655-665.

4. Figueroa Pedraza D, Queiroz D, Sales MC. Doenças infecciosas em crianças pré-escolares brasileiras assistidas em creches. Cien Saude Colet 2014; 19(2):501-518.

5. Pereira AS, Lanzillotti HS, Soares EA. Frequência à creche e estado nutricional de pré-escolares: uma revisão sistemática. Rev Paul Pediatr 2010; 28(4):366-372.

6. Vasconcelos RM, Tancredi RCP, Marin VA. Políticas e normativas aplicadas às creches municipais do Rio de Janeiro. Cien Saude Colet 2013; 18(11):3281-3290.

7. Bógus CM, Nogueira-Martins MCF, Moraes DEB, Taddei JAAC. Cuidados oferecidos pelas creches: percepções de mães e educadoras. Rev Nutr 2007; 20(5):499514.

8. Jef L Leroy, Gadsden P, Maite Guijarro. The impact of daycare programs on child health, nutrition and development in developing countries: a systematic review. Washington: International Food Policy Research Institute; 2011.

9. Figueroa Pedraza D, Rocha ACD, Sales MC. Deficiência de micronutrientes e crescimento linear: revisão sistemática de estudos observacionais. Cien Saude Colet 2013; 18(11):3333-3347.

10. Segall-Corrêa AM, Gonçalves NNS, Chalita LVAS, Russo-Leite GP, Padovani CR, Gonçalves A. Determinantes da evolução do peso e altura em crianças de 3 meses a 6 anos assistidas em creche: análise por modelo linear não hierarquizado em ensaio quase-experimental. Rev Panam Salud Publica 2002; 12(1):19-25.

11. Oliveira MN, Brasil ALD, Taddei JAAC. Avaliação das condições higiênico-sanitárias das cozinhas de creches públicas e filantrópicas. Cien Saude Colet 2008; 13(3):1051-1060.

12. Cavalcante AAM, Priore SE, Franceschini SCC. Estudos de consumo alimentar: aspectos metodológicos gerais e o seu emprego na avaliação de crianças e adolescentes. Rev Bras Saude Matern Infant 2004; 4(3):229-240.

13. Monteiro CA, Benicio MH, Konno SC, Silva ACF, Lima AL, Conde WL. Causes for the decline in child under-nutrition in Brazil, 1996-2007. Rev Saude Publica 2009; 43(1):35-43.

14. Monteiro CA, Benicio MH, Conde WL, Konno S, Lovadino AL, Barros AJD, Victora CG. Narrowing socioeconomic inequality in child stunting: the Brazilian experience, 1974-2007. Bull World Health Organ 2010; 88(4):305-311.

15. Brasil. Ministério da Saúde (MS). Pesquisa Nacional de Demografia e Saúde da Criança e da Mulher 2006: Resultados sobre anemia e hipovitaminose A no Brasil. Brasília: MS; 2009.

16. Sales MC, Figueroa Pedraza D. Parâmetros bioquímicos do estado nutricional de micronutrientes e seu significado para as ações de saúde pública. REpS 2013; 14(1 e 2):94-103.
17. Magalhães P, Ramalho RA, Colli C. Deficiência de ferro e de vitamina A: avaliação nutricional de pré-escolares de Viçosa (MG/Brasil). Nutrire 2001; 21:41-56.

18. Silva LSM, Giugliani ERJ, Aerts DRGC. Prevalência e determinantes de anemia em crianças de Porto Alegre, RS, Brasil. Rev Saude Publica 2001; 35(1):66-73.

19. Brunken GS, Guimarães LV, Fisberg M. Anemia em crianças menores de 3 anos que freqüentam creches públicas em período integral. J Pediatr 2002; 78(1):5056.

20. Silva-Santana SC, Diniz AS, Lóla MMF, Oliveira RS, Silva SMM, Oliveira SF, Kolsteren P. Parameters of evaluation of zinc nutritional status: comparison between zinc hair rates and serum alkaline phosphatase in pre-scholars of the Municipality of João Pessoa, Paraíba. Rev Bras Saude Mater Infant 2002; 2(3):275-282.

21. Almeida CAN, Ricco RG, Del Ciampo LA, Souza AM, Pinho AP, Oliveira JED. Fatores associados a anemia por deficiência de ferro em crianças pré-escolares brasileiras. J Pediatr 2004; 80(3):229-234.

22. Castro TG, Novaes JF, Silva MR, Costa NMB, Franceschini SCC, Tinôco ALA, Leal PFG. Caracterização do consumo alimentar, ambiente socioeconômico e estado nutricional de pré-escolares de creches municipais. Rev Nutr 2005; 18(3):321-330.

23. Fernandes TFS, Diniz AS, Cabral PC, Oliveira RS, Lóla MMF, Silva SMM, Kolsteren P. Hipovitaminose A em pré-escolares de creches públicas do Recife: indicadores bioquímico e dietético. Rev Nutr 2005; 18(4):471-480.

24. Matta IEA, Veiga GV, Baião MR, Santos MMAS, Luiz RR. Anemia em crianças menores de cinco anos que freqüentam creches públicas do município do Rio de Janeiro, Brasil. Rev Bras Saude Mater Infant 2005; 5(3):349-357.

25. Bueno MB, Selem SSC, Arêas JAG, Fisberg RM. Prevalência e fatores associados à anemia entre crianças atendidas em creches públicas de São Paulo. Rev Bras Epidemiol 2006; 9(4):462-470.

26. Almeida CAN, Ramos APP, João CA, João CR, Ricco RG, Dutra-de-Oliveira JE. Jardinópolis sem anemia, primeira fase: avaliação antropométrica e do estado nutricional de ferro. Rev Paul Pediatr 2007; 25(3):254257.

27. Vieira ACF, Diniz AS, Cabral PC, Oliveira RS, Lóla MMF, Silva SMM, Kolsteren P. Avaliação do estado nutricional de ferro e anemia em crianças menores de 5 anos de creches públicas. J Pediatr 2007; 83(4):370-376.

28. Rocha DS, Lamounier JA, Capanema FD, Franceschini SCC, Norton RC, Costa ABP, Rodrigues MTG, Carvalho MR, Chaves TS. Estado nutricional e prevalência de anemia em crianças que freqüentam creches em Belo Horizonte, Minas Gerais. Rev Paul Pediatr 2008; 26(1):6-13.

29. Camillo CC, Amancio OMS, Vitalle MSS, Braga JAP, Juliano Y. Anemia ferropriva e estado nutricional de crianças de creches de Guaxupé. Rev Assoc Med Bras 2008; 54(2):154-159.

30. Costa CA, Machado EH, Colli C, Latorre WC, Szarfarc SC. Anemia em pré-escolares atendidos em creches de São Paulo (SP): perspectivas decorrentes da fortificação das farinhas de trigo e de milho. Nutrire 2009; 34(1):59-74. 
31. Konstantyner T, Taddei JAAC, Oliveira MN, Palma D, Colugnati FAB. Riscos isolados e agregados de anemia em crianças frequentadoras de berçários de creches. $J$ Pediatr 2009; 85(3):209-216.

32. Carvalho AGC, Lira PIC, Barros MFA, Aléssio MLM, Lima MC, Carbonneau MA, Berger J, Léger CL. Diagnosis of iron deficiency anemia in children of Northeast Brazil. Rev Saude Publica 2010; 44(3):513-519.

33. Azevedo MMS, Cabral PC, Diniz AS, Fisberg M, Fisberg RM, Arruda IKG. Deficiência de vitamina A em pré-escolares da cidade do Recife, Nordeste do Brasil. ALAN 2010; 60(1):36-41.

34. Figueroa Pedraza D, Rocha ACD, Queiroz EO, Sousa CPC. Estado nutricional relativo ao zinco de crianças que frequentam creches do estado da Paraíba. Rev Nutr 2011;24(4):539-552.

35. Rodrigues VC, Mendes BD, Gozzi A, Sandrini F, Santana RG, Matioli G. Deficiência de ferro, prevalência de anemia e fatores associados em crianças de creches públicas do oeste do Paraná, Brasil. Rev Nutr 2011; 24(3):407-420.

36. Figueroa Pedraza D, Rocha ACD, Sousa CPC. Crescimento e deficiências de micronutrientes: perfil das crianças assistidas no núcleo de creches do governo da Paraíba, Brasil. Cien Saude Colet 2013; 18(11):33793390.

37. Oliveira TSC, Silva MC, Santos JN, Rocha DS, Alves CRL, Capanema FD, Lamounier JA. Anemia entre pré -escolares - um problema de saúde pública em Belo Horizonte, Brasil. Cien Saude Colet 2014; 19(1):59-66.

38. Canella DS, Silva ACF, Jaime PC. Produção científica sobre nutrição no âmbito da Atenção Primária à Saúde no Brasil: uma revisão de literatura. Cien Saude Colet 2013; 18(2):297-308.

39. Ramakrishnan U, Nguyen P, Martorell R. Effects of micronutrients on growth of children under $5 \mathrm{y}$ of age: meta-analyses of single and multiple nutrient interventions. Am J Clin Nutr 2009; 89(1):191-203.

40. Figueroa Pedraza D, Sales MC. Avaliação de desempenho das concentrações capilares de zinco como método diagnóstico da deficiência de zinco: um estudo comparativo com as concentrações séricas de zinco. Rev Nutr 2013; 26(6):617-624.

41. Milagres RCRM, Nunes LC, Pinheiro-Sant'Ana HM. A deficiência de vitamina A em crianças no Brasil e no mundo. Cien Saude Colet 2007; 12(5):1253-1266.

42. World Health Organization (WHO). Global prevalence of vitamin A deficiency in populations at risk 1995-2005. WHO Global Database on Vitamin A Deficiency. Geneva: WHO; 2009.

43. Ramalho A, Padilha P, Saunders C. Análise crítica de estudos brasileiros sobre deficiência de vitamina A no grupo materno-infantil. Rev Paul Pediatr 2008; 26(4):392-399.

44. Queiroz D, Paiva AA, Figueroa Pedraza D, Cunha MAL, Esteves GH, Luna JG, Diniz AS. Deficiência de vitamina A e fatores associados em crianças de áreas urbanas. Rev Saude Publica 2013; 47(2):248-256.

45. Figueroa Pedraza D, Sales MC. Influência da inflamação subclínica sobre marcadores bioquímicos do estado nutricional de micronutrientes importantes no crescimento linear. RCFBA 2015; 36(1):103-109.
46. Batista Filho M, Souza AI, Bresani CC. Anemia como problema de saúde pública: uma realidade atual. Cien Saude Colet 2008; 13(6):1917-1922.

47. Batista Filho M, Souza AI, Miglioli TC, Santos MC Anemia e obesidade: um paradoxo da transição nutricional brasileira. Cad Saude Publica 2008; 24(Supl. 2):S247-S257.

48. World Health Organization (WHO). Iron Deficiency Anaemia: Assessment, Prevention and Control - A guide for programme managers. Geneva: WHO; 2001.

49. Oliveira CSM, Cardoso MA, Araújo TS, Muniz PT. Anemia em crianças de 6 a 59 meses e fatores associados no Município de Jordão, Estado do Acre, Brasil. Cad Saude Publica 2011; 27(5):1008-1020.

50. Duarte LS, Fujimori E, Minagawa AT, Schoeps FA, Montero RMJM. Aleitamento materno e níveis de hemoglobina em crianças menores de 2 anos em município do estado de São Paulo, Brasil. Rev Nutr 2007; 20(2):149-157.

51. Vieira RCS, Ferreira HS, Costa ACS, Moura FA, Florêncio TMMT, Torres ZMC. Prevalência e fatores de risco para anemia em crianças pré-escolares do Estado de Alagoas, Brasil. Rev Bras Saude Mater Infant 2010; 10(1):107-116.

52. Bortolini GA, Vitolo MR. Importância das práticas alimentares no primeiro ano de vida na prevenção da deficiência de ferro. Rev Nutr 2010; 23(6):1051-1062.

53. Grotto HZW. Diagnóstico laboratorial da deficiência de ferro. Rev Bras Hematol Hemoter 2010; 32(Supl. 2):22-28.

54. Neufeld L, Garcia-Guerra A, Sánchez-Francia D, Newton-Sánchez O, Ramirez-Villalobos MD, Rivera-Dommarco J. Hemoglobin measured by HemoCue and a reference method in venous and capillary blood: a validation study. Salud Publica Mex 2002; 44(3):219-227.

55. Neves MB, da Silva EM, de Morais MB. Prevalence and factors associated with iron deficiency in infants treated at a primary care center in Belém, Pará, Brazil. Cad Saude Publica 2005; 21(6):1911-1918.

56. Silva DG, Priore SE, Franceschini SCC. Risk factors for anemia in infants assisted by public health services: the importance of feeding practices and iron supplementation. J Pediatr 2007; 83(2):149-156

57. Leal LP, Osório MM. Fatores associados à ocorrência de anemia em crianças menores de seis anos: uma revisão sistemática dos estudos populacionais. Rev Bras Saude Mater Infant 2010; 10(4):417-439.

58. Jordão RE, Bernardi JLD, Barros Filho AA. Prevalência de anemia ferropriva no Brasil: uma revisão sistemática. Rev Paul Pediatr 2009; 27(1):90-98.

59. Oliveira MC, Vassimon HS. Programa Nacional de Alimentação Escolar e sua aceitação pelos alunos: uma revisão sistemática. Investigação 2012; 12(1):4-10.

Artigo apresentado em 17/09/2014

Aprovado em 15/05/2015

Versão final apresentada em 17/05/2015 
